\title{
A hypothetical future in rheumatology: will we miss steroids in a steroid free-world?
}

\author{
Sakir Ahmed ${ }^{1}$ (D) \\ Received: 30 March 2021 / Accepted: 30 April 2021 / Published online: 11 May 2021 \\ (c) The Author(s), under exclusive licence to Springer-Verlag GmbH Germany, part of Springer Nature 2021
}

The recently published phase III trial of avacopan in ANCAassociated vasculitis has opened up avenues for steroid-free management of small vasculitis [1]. A similar promise is being explored in the context of lupus nephritis [2]. Mulling over a rheumatology world free of steroids, and influenced by a piece on big-data and artificial intelligence-based futuristic diagnostics [3], I envisaged a hypothetical doctor, Timothy, of the future who wonders how the steroid era would have been.

The aim of the letter is to highlight two points in the management of lupus. The first is that despite numerous new drugs being explored, there still difficult cases that do not respond to conventional drugs. The second is envisaging a future where lupus can be managed without the use of corticosteroids. In such a world, if the treating physician comes across a truly refractory case of lupus nephritis, will she (or he) have to still fall back on this, by-then, obsolete drug?

Beyond this, the letter is a free run of the imagination based on known concepts in lupus.

\section{The future}

Timothy is a lupimmunologist whose job is to provide personalised precision medicine-based therapeutic options to lupus patients and anticipate prognosis and treatmentrelated complications. He is baffled by one lupus patient with nephritis who appears to be potentially refractory to all available therapies and discusses the case with his senior colleague Yuri who is a glomerulorheumatologist, a rheumatologist dealing with diseases affecting the renal glomerular system.

Sakir Ahmed

sakir005@gmail.com

1 Department of Clinical Immunology and Rheumatology, Kalinga Institute of Medical Sciences (KIMS), KIIT

University, Bhubaneswar 751024, India
"I am simply baffled by this lady without any BAFF transcriptome signature in her serum" Timothy explains to Yuri, "Her genomics show that her interferon-stimulated gene set has an odd combination of single-nucleotide polymorphisms that will make all available anti-interferon therapies or FOXP3 induction ineffective for her lupus. She has a coronavirus integrated with her neuronal genome that makes complement-based therapies risky. Her proteasome analysis showed a less than $20 \%$ success rate if we use proteasome based therapies. She has received very-high-specific T cell depletion (VHS-TCD) therapy once but due to high rates of somatic hypermutation she had a type II T-cell escape. Now I am not able to find out adequate treatment for her. I wish I had some concoction that could target all pathways at once. Just to buy us some time so that we can map her T-cell hypermutation landscape. That will allow us to prepare 'emulating Chimeric antigen receptor T cells', that is eCAR T cells, to combat her pathological T cells."

Yuri asked, "How long do you predict she will have irreversible nephron loss? And how long will it take to prepare eCAR-T cells?".

"Oh, she has rising RHYME cells and with collagen associated metabolome in her urine. I estimate renal scarring will start within 10 days. The eCAR T cells will take 3 months of preparation in the best of labs. It takes time to train the artificial intelligence of the eCAR T cells to identify and match the host's pathological T cells." The RHYME cells Timothy referred to were Rhinovestibular Hypermodulated Young Mesenchymal cells whose methylation patterns changes with immune activation and could be used to predict upcoming immune events in the body. They could be collected by a soft cellular collector (SCC) from the nose. All lupus patients used one for weekly monitoring to predict various upcoming flares. Timothy's patient's SCC had warned him of impending rapidly progressive glomerulonephritis a couple of days ago. And Timothy was now at his wits' end on how to control the flare till the eCAR T cells were ready. Yuri, with his years of experience, smiled and said, "We never always have 
the answer in the case of lupus. Did you know one of the body's hormones, cortisol, or its analogues were once used to treat lupus? In my days in medical school, I had heard of Prof Rebecca Chen talk about how they had once used mega doses of those drugs, corticosteroid analogues, for induction of lupus nephritis. Those were the days when they actually introduced a needle into the kidneys to get a biopsy. Give that a thought Tim!".

So Timothy went back and commanded the search engine Googlplex to compile a summary on corticosteroids and lupus. He was amazed by the results! The wonder drug "Compound E" that seemed a panacea for all rheumatology illnesses after its first use in rheumatoid arthritis, had led to a Nobel prize in 1950 , almost a century before he was born. He marvelled at the widespread use despite gradual knowledge about adverse effects.

The drug changed rheumatology practice and was almost indispensable for the next 5-8 decades. First, safer alternatives had come in: selective glucocorticoid receptor modulators. Then targeted therapies came in. First targeting specific pathways, then S2-targeted therapies, for specific targets in specific cells only. These gradually phased out all steroid from clinical use and then gradually from medical SEKBs (standard electronic knowledge banks).

So Timothy had found an answer. Or had he? He felt the same thrill and fear hundreds of physicians had felt when they tried something novel for a very difficult case of lupus. Only, it was not novel for medical science, just novel for his era. He would try it along with a suggested proteasome targeted therapy. Perhaps it would buy his patient the necessary time to get the eCAR-T cells ready...

\section{Author's note}

RHYME cells are a figment of the imagination inspired by the recently described PRIME cells that might have a role in predicting flares in rheumatoid arthritis [4]. So also, eCAR $\mathrm{T}$ cells do not exist (yet) like rest of the imagined targeted therapies. There is emerging evidence that therapies based on CAR-T cells [5, 6] or those targeting complement pathways [7], proteasome [8] and interferons [9] may be useful in difficult cases of lupus nephritis. FOXp3 and interleukin-10 expression correlates with disease activity [10]. Targeting BAFF (B cell activating factor) has been shown to be beneficial in lupus nephritis [11].

This is a projected future based on these known concept with a leap of imagination. Some of these may come true in one form or the other, and provide us unique tools to combat difficult lupus. Till then, it is still a dream for the majority of rheumatologists to think of treating lupus without any steroids.
Author contribution The entire work has been drafted and revised by Sakir Ahmed.

\section{Declarations}

Conflict of interest Dr Ahmed has received speaker fees from Pfizer (unrelated to the current work). He has no other potential conflicts of interest.

\section{References}

1. Jayne DRW, Merkel PA, Schall TJ, Bekker P (2021) Avacopan for the treatment of ANCA-associated vasculitis. N Engl J Med 384:599-609. https://doi.org/10.1056/NEJMoa2023386

2. Condon MB, Ashby D, Pepper RJ et al (2013) Prospective observational single-centre cohort study to evaluate the effectiveness of treating lupus nephritis with rituximab and mycophenolate mofetil but no oral steroids. Ann Rheum Dis 72:1280-1286. https://doi. org/10.1136/annrheumdis-2012-202844

3. Burmester GR (2018) Rheumatology 4.0: big data, wearables and diagnosis by computer. Ann Rheum Dis 77:963-965. https://doi. org/10.1136/annrheumdis-2017-212888

4. Orange DE, Yao V, Sawicka K et al (2020) RNA identification of PRIME cells predicting rheumatoid arthritis flares. N Engl J Med 383:218-228. https://doi.org/10.1056/NEJMoa2004114

5. Kansal R, Richardson N, Neeli I et al (2019) Sustained B cell depletion by CD19-targeted CAR T cells is a highly effective treatment for murine lupus. Sci Transl Med 11:eaav1648. https:// doi.org/10.1126/scitranslmed.aav1648

6. Ahmed S (2019) CAR T-cells to drive away autoimmunity in lupus. Indian J Rheumatol 14:177-179. https://doi.org/10.4103/ injr.injr_118_19

7. Trouw LA, Pickering MC, Blom AM (2017) The complement system as a potential therapeutic target in rheumatic disease. Nat Rev Rheumatol 13:538-547. https://doi.org/10.1038/nrrheum. 2017.125

8. Alexander T, Sarfert R, Klotsche J et al (2015) The proteasome inhibitior bortezomib depletes plasma cells and ameliorates clinical manifestations of refractory systemic lupus erythematosus. Ann Rheum Dis 74:1474-1478. https://doi.org/10.1136/annrh eumdis-2014-206016

9. Chasset F, Arnaud L (2018) Targeting interferons and their pathways in systemic lupus erythematosus. Autoimmun Rev 17:44-52. https://doi.org/10.1016/j.autrev.2017.11.009

10. Miteva LD, Manolova IM, Ivanova MG et al (2020) High interleukin-18 and low FOXP3 mRNAs in peripheral blood of women with severe systemic lupus erythematosus: a cross-sectional study. Rheumatol Int 40:727-735. https://doi.org/10.1007/ s00296-020-04542-3

11. Furie R, Rovin BH, Houssiau F et al (2020) Two-year, randomized, controlled trial of belimumab in lupus nephritis. N Engl J Med 383:1117-1128. https://doi.org/10.1056/NEJMoa2001180

Publisher's Note Springer Nature remains neutral with regard to jurisdictional claims in published maps and institutional affiliations. 